\title{
SHIP HANDLING IN CASE OF DISTURBANCE DURING SEQUENTIAL CALCULATION AND OBSERVATION OF SHIP MOTION
}

\section{УПРАВЛІННЯ СУДНОМ ЗА ЗБУРЕННЯМ ПРИ ПОСЛІДОВНОМУ ЗЧИСЛЕННІ ТА ОБСЕРВАЦІЇ РУХУ СУДНА}

\author{
K.O. Siniuta, assistant, PhD student \\ К.О. Сінюта, асистент, аспірант \\ National university “Odessa maritime academy”, Ukraine \\ Національний університет «Одеська морська академія», Украӥна
}

\begin{abstract}
Controllability is an important maritime quality that determines the efficiency of ship handling. When developing course control systems, it is necessary to take into account the operational characteristics of the vessel, as well as external factors affecting it. The complexity of ship handling, as an object of handling, arises due to the continuous influence of various factors that affect the controllability of the ship. The environmental conditions in which the course management task has to be solved are diverse - stormy weather, ice conditions, shallow water, tides, restricted waters(congested areas), proximity of other vessels, etc. All these factors cannot be comprehensively taken into account by traditional mathematical methods, while ensuring the necessary adequacy of real processes.

This paper considers existing approaches to controlling the movement of a ship on a course, such as course control, disturbance control, ship movement control on a course based on the principle of long-term prediction, lateral deviation, intellectual approaches to ship control.

The most necessary way to improve the quality of the vessel's course is to control the disturbance by consistently calculating and observing the vessel's movement. The main disturbing effect in stabilizing the course is caused by sea waves. In stormy weather, forced oscillations are imposed on the ship's own motions on the course. The amplitude and period of yawing depend on the level of sea state, the direction and strength of the wind, the tonnage of the vessel, its loading condition, speed, effectiveness of the rudder and the law of control. There is a need to increase the accuracy of determining the direct relationship between the measured value of the external perturbation and the magnitude of the yaw angle.

The article provides an algorithm for calculating the return of the vessel to the path line, taking into account the modulus and direction of natural disturbance obtained as a result of observation of the ship's position.
\end{abstract}

Keywords: controllability, perturbation, deviation.

\section{РЕФЕРАТ}

Керованість - важлива морська якість, щзо визначає ефективність управління судном. При розробиі систем управління курсом необхідно максимально повністю враховувати експлуатаційні характеристики самого судна, а також зовнішні фактори, щзо впливають на нього. Складність управління судном, як об'єктом управління, виникає через безперервний вплив різних факторів, щуо впливають на керованість судна. Умови зовнішнього середовища, в яких доводиться вирішувати завдання управління курсом, носять різноманітний характер штормова погода, льодова обстановка, мілководдя, приливні явища, стислі умови, наявність інших суден і т.д. Всі иі фактори комплексно враховувати традиційними математичними методами, забезпечивщи при цуьому необхідну адекватність реальних процесів, неможливо. 
У изій роботі розглянуто існуючі підходи до управління рухом судна на курсі такі як курсовий спосіб управління, управління за збуренням, управління рухом судна на курсі на основі принщииу довгострокового прогнозування, управління за відхиленням, інтелектуальні підходи до управління судами.

Найбільш необхідним способом підвищити якість утримання судна на курсі $\epsilon$ управління за збуренням при послідовному зчисленні та обсерващії руху судна. Основна збурююча дія при стабілізаиії на курсі викликана морським хвилюванням. У штормову погоду на власні коливання судна на курсі накладаються вимушені коливання - нишпорення. Амплітуда і період нишпорення залежать від ступеня хвилювання, напрямку і сили вітру, водотоннажності судна, його завантаження, швидкості, ефективності дії керма $i$ закону управління ім. Існує необхідність збільшення точності визначення прямого зв'язку між виміреним значенням зовнішнього збурення і величиною кута нишпорення

У статті запропоновано алгоритм розрахунку повернення судна на лінію иляху 3 урахуванням модулю та напрямку природнього збурення, отриманого у результаті проведення обсерващії місия судна.

Ключові слова: керованість, збурення, відхилення.

\section{Постановка проблеми в загальному вигляді та ї̈ зв'язок із важливими науковими чи практичними завданнями}

Актуальною проблема керованості морських суден залишається і досі, про що свідчить велика кількість робіт з цієї теми. Такий інтерес пояснюється насамперед тим, що з'являються нові типи суден і суднових рушіїв, розширюються можливості обчислювальної техніки, розробляються нові принципи управління судами, впроваджуються системи підтримки прийняття рішень. Основна проблема полягає в тому, що динаміка судна в загальному вигляді дуже складна. Тому для ії математичного опису вдаються до низки спрощень. Деякі з них досить суттєві, особливо, що стосуються поведінки судна при дії зовнішніх збурень, наприклад - в умовах морського хвилювання.

У попередньому дослідженні [1] був розроблений ефективний алгоритм обліку векторів течії та вітро-хвильового збурення в початковій точці шляху судна, вважаючи модуль відносної швидкості судна постійним. У роботі наведено модель визначення елементів руху судна у вигляді алгоритму, що представляє послідовність операторів присвоєння, та операторів вводу, друку та виходу, складають блок-схему його програмної реалізації. У роботі наведено так само алгоритм розрахунку модулів і внутрішніх кутів векторного трикутника, утвореного в результаті обсервації.

Наступний крок полягає у визначенні швидкості обсервованного збурення і визначення елементів швидкісного трикутника при переході до наступної зчислимої точки, а також стоїть проблема здійснення подальших зчислень до пункту підходу до точки призначення. Проблема руху судна по координатним точкам відповідної лінії заданого курсу пов'язана зі швидкісними втратами.

\section{Формування мети роботи та постановка завдань дослідження}

Мета дослідженні полягає у розробці ефективного алгоритму розрахунку повернення судна на лінію маршруту з урахуванням модулю та напрямку природнього збурення, отриманого у результаті проведення обсервації місця судна.

Об'єктом дослідження став процес руху судна, а предметом - елементи (параметри) pyxy.

Актуальність роботи полягає у дослідженні шляхових втрат при русі судна по координатним точкам відповідної лінії заданого курсу та знаходження середньоквадратичної похибки зчислення та геометричної вірогідності. 
Аналіз останніх досліджень і публікацій, в яких започатковано розв'язання даної проблеми і виділення невирішених раніше частин загальної проблеми

Питання керованості морських суден за курсом досліджені і висвітлені в літературі досить повно. Багато авторів тією чи іншою мірою присвятили свої роботи проблемі, серед яких необхідно виділити роботи T.I. Фоссена [2], О.Д. Піпченко [3].

У роботі [5] розглянуто курсовий спосіб управління (рис 1(a)) $K K_{\text {зад }}=I K+\Delta K$, при якому судно управляється по компасу, без урахування зовнішніх збурень і обставин плавання, рух без судна між путьовими точками не коригується. При такому способі відхилення від наміченого шляху відбувається за рахунок дії як зовнішніх, так і внутрішніх факторів максимально, планова траєкторія не враховується. Судно ніколи не прийде в пункт призначення, хоча він використовується на відрізках шляху між обсерваціями. У роботі також наведений спосіб управління за відхиленням (рис 1(в)) $K K_{\text {зад }}=I K_{1}+\Delta K$, при якому курс судна змінюється щоразу, коли проводиться визначення місця і встановлюється, що відбулося неприпустиме зміщення відносно планованої траєкторії. Перерахунок курсу ІК 1 проводиться за поточним значенням координат і подальшої подорожньої точки, і чим частіше визначається місце, тим точніше судно вийде в намічену точку.

3 аналізу джерел, можна виділити два основних напрямки: традиційний підхід $[2,4,5]$ та застосування концепції «м'яких обчислень», а саме використання нейронних мереж, нечіткої логіки та еволюційних (генетичних) алгоритмів [3, 5, 6, 7]. Подібні підходи до управління рухом судна поки освітлені мало, проте кількість робіт, присвячених цій темі, 3 кожним роком збільшується. В основному, ідеї штучного інтелекту пропонується реалізувати при створенні систем підтримки прийняття рішень судноводія в складних ситуаціях управління судном. До таких ситуацій відносять: вибір оптимального маршруту; оцінка ризиків; управління рухом судна на траєкторії.

Основну увагу слід приділити управлінню курсом судна за збуренням. Основну збурюючу дію при управлінні судном на курсі та його стабілізації надає морське хвилювання. Облік гідрометеорологічних факторів при плаванні суден обов'язковий для судноводіїв i недооцінка цього найважливішого компонента при опрацюваннях маршруту переходу [8] може призвести до катастрофічних наслідків [9].

В результаті аналізу публікацій, була виявлена необхідність вирішення задачі стабілізації судна на маршруті створенням швидкого та надійного методу при послідовному зчисленні з урахуванням природних збурень та обсервації руху судна.

\section{Виклад основного матеріалу дослідження 3 повним обгрунтуванням отриманих наукових результатів}

Дослідження в галузі управління судном на курсі та маршруті важливі в області управління рухом судна, в якій точність управління курсом судна завжди була актуальною проблемою.

Через невизначені зовнішні впливи, такі як вітер, хвилювання, перебіг і велика інерція, затримки і нелінійність самого судна, які роблять параметри судна невизначеними, при керуванні курсом судна виникають певні труднощі.

У попередньому дослідженні [1] був запропонований алгоритм обліку векторів течії $\left(\overline{V_{T}}\right)$

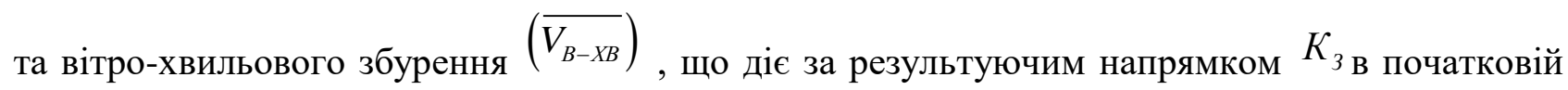
точці шляху судна для першого проміжку часу на проміжку $\Delta t=1$ год., вважаючи модуль відносної швидкості судна постійним $\overline{V_{C}}=$ const . Сумарним вектором переміщення є вектор шляху, який діє у напрямку $K_{\amalg}$. Так само у роботі був наведений метод визначення елементів руху судна у вигляді алгоритму та блок-схема його програмної реалізації. 
Наступний крок дослідження полягає у визначенні швидкості обсервованного збурення і визначення елементів швидкісного трикутника при переході до наступної зчислимої точки, а також стоїть завдання здійснення подальших зчислень до пункту підходу до точки призначення.

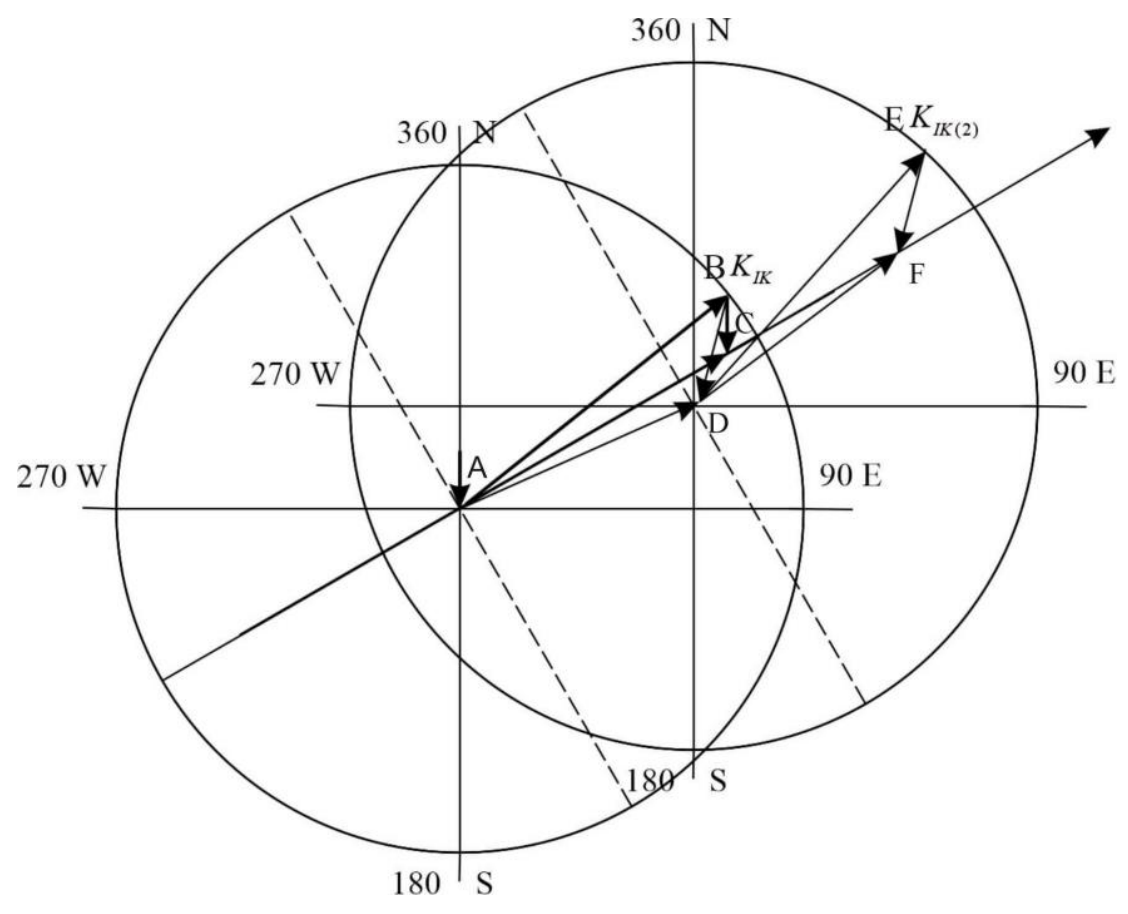

Рис 1. Графічне зображення повернення судна на лінію шляху за наступний проміжок чacy

Після проходження першого проміжку часу було проведено обсервацію місця судна. В результаті, за відомими координатами були розраховані кути та сторони обсервованного трикутника. Стоїть завдання повернення на лінію шляху за наступний проміжок часу 3 урахуванням незмінної швидкості ходу судна та збереженням модуля та напрямку обсервованного вектору зовнішнього збурення. При вирішенні цього завдання було обрано найпростіший та швидкодіючий спосіб розрахунку.

Введемо позначення А, B, C, D, E, F

Координати т. $\mathrm{A}\left(x_{A}, y_{A}\right)=V_{C(1)}\left(\varphi_{V_{C(1)}}, \lambda_{V_{C(1)}}\right)$

Координати т. $\mathrm{B}\left(x_{B}, y_{B}\right)=V_{C(2)}\left(\varphi_{V_{C(2)}}, \lambda_{V_{C(2)}}\right)$

Координати т. $\mathrm{C}\left(x_{C}, y_{C}\right)=V_{U}\left(\varphi_{V_{U}}, \lambda_{V_{U}}\right)$

Координати т. $\mathrm{D}\left(x_{D}, y_{D}\right)=V_{U(O)}\left(\varphi_{V_{U}(O)}, \lambda_{V_{\amalg(O)}}\right)$

Координати т. $\mathrm{E}\left(x_{E}, y_{E}\right)=V_{C(\mathrm{II})}\left(\varphi_{C(\mathrm{II})}, \lambda_{C(\mathrm{II})}\right)$

Координати т. $\mathrm{F}\left(x_{F}, y_{F}\right)=V_{U(\mathrm{II})}\left(\varphi_{V_{U(\mathrm{II})}}, \lambda_{V_{U(\mathrm{II})}}\right)$

$V_{C(1)}, V_{C(2)}=\overline{\left|V_{C}\right|}, V_{C(2)}, V_{U I}=\overline{\left|V_{3}\right|}, V_{C(2)}, V_{U(O)}=\overline{\left|V_{3(O)}\right|}, V_{U(O)}, V_{C(1)}=\overline{\left|V_{U(O)}\right|}$

Оскільки $\mathrm{BD}=\mathrm{EF}$ та $B D \| E F$, то чотирикутник $\mathrm{DBEF}$ - паралелограм і $\mathrm{BE}=\mathrm{DF}$ та $B E \| D F$

Визначаємо кут нишпорення 


$$
p=\angle B A D-\angle B A C
$$

При переході на наступну ділянку шляху визначаємо істинний курс судна

$$
K_{I K\left(C_{2}\right)}=K_{I K\left(C_{1}\right)}-2 p
$$

Для знаходження кута BDE необхідно визначити кут між N (нордом) та вектором обсервованого збурення BD.

$$
\begin{gathered}
\angle B D N=\operatorname{arctg}\left(\left|y_{b}-y_{d}\right| /\left|x_{b}-x_{d}\right|\right), \\
\angle B D E=\angle B N D+K_{I K(C 2)}
\end{gathered}
$$

$\angle B D E=\angle D E F$ як кути при діагоналі паралелограма DBEF.

За теоремою косинусів

$$
D F=\sqrt{D E^{2}+E F^{2}-2 \cdot D E \cdot \cos \angle D E F}=V_{U(C 2)}
$$

За теоремою синусів

$$
\begin{gathered}
\angle E F D=\arcsin (D E \cdot \sin \angle D E F / D F), \\
\angle E D F=180-\angle E F D-\angle D E F
\end{gathered}
$$

Знайдемо координати точок $E\left(x_{E}, y_{E}\right), F\left(x_{F}, y_{F}\right)$.

$$
\begin{gathered}
\left\{\begin{array}{l}
x_{E}=x_{B}+B D \cos \angle B E D, \\
y_{E}=y_{B}+B D \sin \angle B E D .
\end{array}\right. \\
\left\{\begin{array}{l}
x_{F}=x_{D}+B D \cos \angle B E D, \\
y_{F}=y_{D}+B D \sin \angle B E D .
\end{array}\right.
\end{gathered}
$$

Якщо в подальшому обсервовані точки співпадають зі зчислимими, то істинний курс на подальших проміжках часу

$$
K_{I K\left(C_{3}\right)}=K_{I K\left(C_{1}\right)}-p
$$

Шляхова швидкість судна і нові зчисленні координати визначаються як наведено вище.

Якщо виникає відхилення від лінії планового шляху, то процедуру потрібно повторити аналогічнім чином спочатку.

Знайдемо геометричну ймовірність. Геометрична ймовірність події $\mathrm{A}$, що $\epsilon$ підмножиною $\Omega$ точок на прямій або площині - це відношення площі фігури А до площі всієї множини $\Omega$ : Формула геометричної ймовірності

$$
P(A)=S(A) / S(\Omega)
$$


де A - судно знаходиться у трикутнику допустимого відхилення (трикутника, утвореного швидкістю ходу, швидкістю маршруту та допустимим бічним відхиленням залежно від умов та обставин плавання).

Імовірність безпечного місцезнаходження судна при будь-якому законі розподілу випадкових похибок у загальному випадку залежить від співвідношення допустимої в умовах похибки в місці судна і фактичною кількісною оцінкою точності місця. За допустиму похибку приймається детермінована величина, що дорівнює найкоротшій відстані між судном та навігаційною небезпекою. Найкоротша відстань до навігаційної небезпеки є зоною безпечною від зіткнення з цією небезпекою. Тому відстань визначає межу допустимої безпечної зони.

Як кількісну оцінку похибки місця судна використовується, як правило, середня квадратична похибка.

$$
\sigma=\sqrt{\frac{\sum\left(x_{i}-\bar{x}\right)^{2}}{n}},
$$

де $x_{i}$ - окремі значення, $\bar{x}$ - середнє арифметичне за вибіркою.

\section{Висновки та перспективи подальшої роботи по даному напрямку}

Динаміка судна в загальному вигляді досить складна, тому для іiї математичного опису вдаються до ряду спрощень, деякі з них (особливо стосуються поведінки судна в умовах морського хвилювання) досить істотні. Ступінь допустимості таких спрощень залежить від умов плавання судна. Різноманіття впливають на керованість факторів (завантаження, швидкість, хвилювання та ін.) також ускладнює математичне уявлення судна і знижує ступінь адекватності використовуваних для цього спрощених математичних моделей.

Обертально-поступальний рух судна 3 відхилення є необхідним, але недостатньою умовою руху судна так як воно враховує тільки нормальний вплив зовнішнього збурення без урахування його напряму. Подальший розвиток досліджень необхідно спрямувати на зовнішнє збурення, формуючи регулювання за збуренням та визначення ефективності наведеного методу при натурних випробуваннях. Визначені координатним методом елементи векторів розрахункового та фактичного шляхового та швидкісного трикутників дозволяють вирішувати більш складні завдання графоаналітичного і мехатронного зчислення та обсервації поступально-обертового руху судна по маршруту, але й удосконалювати управління по зниженню рискання на курсі при дії збурень у «великому» за реальним часом, зі змінним інтервалом обсервацій, наближаючись до інваріантного та робастного управління.

\section{ЛITЕРАТУРА}

1. Сінюта К.О. Ітераційний метод стабілізації судна на курсі та маршруті [текст] / К.О. Сінюта // Судноводіння: Зб. наук. праць / НУ «ОМА»- Вип. 31. - Одеса: «ВидавІнформ», 2021. - C.117-124.

2. Fossen T. I. Marine Control Systems. Guidance, Navigation and Control of Ships, Rigs and Underwater Vehicles. Marine Cybernetics. Trondheim, Norway, 2002. 570 p.

3. Пипченко А. Д. Математическое моделирование динамики судна на базе искусственной нейронной сети. Судовождение: Сб. научн. трудов ОНМА.

2006. Вып. 12. С. 84-92.

4. Мальцев А.С. Методологические основы маневрирования судов при сближении // А.С. Мальцев, В.В. Голиков, И.В. Сафин и др. - Одесса: ОНМА, 2013. — 218 с. 
5. Подпорин С. А. Нейронный управляющий контроллер в задаче автоматического управления судном на меняющемся курсе. Судовождение: Сб. научн. трудов ОНМА. 2011. Вып. 19. С. 156-165.

6. Chen W. Q., Chen J., Zhang W. (2016): Adaptive Neural Network Robust Tracking Control for Ship Course. Ship Engineering, 9, 15-20.

7. E. W. McGookin, D. J. Murray-Smith, Y. Li, and T. I. Fossen, "Ship steering control system optimization using genetic algorithms," J. Control Eng. Practice, vol. 8, pp. 429-443, 2000.

8. Смоленцев О. И. Методы расчета вынужденных потерь скорости судна на встречном волнении, связанные с нормированием слеминга и заливаемости / О. И. Смоленцев // Электронный вестник. - 2011. - № 4. - С. 18-25.

9. Ершов А. А. От «Титаника» до «Costa Concordia» неиспользованные возможности для спасения: монография / А. А. Ершов. - Saarbrucken, Deutschland: LAPLAMBERT Academic Publishing, 2013. - 146 c.

\section{REFERENCES}

1. Siniuta K.O. Iteratsiinyi metod stabilizatsii sudna na kursi ta marshruti [tekst] / K.O. Siniuta // Sudnovodinnia: Zb. nauk. prats / NU «OMA» - Vyp. 31. - Odesa: «VydavInform», 2021. - S.117-124.

2. Fossen T. I. Marine Control Systems. Guidance, Navigation and Control of Ships, Rigs and Underwater Vehicles. Marine Cybernetics. Trondheim, Norway, 2002. 570 p.

3. Pipchenko A. D. Matematycheskoe modelyrovanye dynamyky sudna na baze yskusstvennoi neironnoi sety. Sudovozhdenye: Sb. nauchn. trudov ONMA.

2006. Vyp. 12. C. 84-92.

4. Maltsev A.S. Metodolohycheskye osnove manevryrovanyia sudov pry sblyzhenyy // A.S. Maltsev, V.V. Holykov, Y.V. Safyn y dr. — Odessa: ONMA, 2013. - 218 s.

5. Podporyn S. A. Neironnyi upravliaiushchyi kontroller $\mathrm{v}$ zadache avtomatycheskoho upravlenyia sudnom na meniaiushchemsia kurse. Sudovozhdenye: Sb. nauchn. trudov ONMA. 2011. Vyp. 19. C. 156-165.

6. Chen W. Q., Chen J., Zhang W. (2016): Adaptive Neural Network Robust Tracking Control for Ship Course. Ship Engineering, 9, 15-20.

7. E. W. McGookin, D. J. Murray-Smith, Y. Li, and T. I. Fossen, "Ship steering control system optimization using genetic algorithms," J. Control Eng. Practice, vol. 8, pp. 429-443, 2000.

8. Smolentsev O. Y. Metodы rascheta vыnuzhdennыkh poter skorosty sudna na vstrechnom volnenyy, sviazannye s normyrovanyem slemynha y zalyvaemosty / O. Y. Smolentsev // Эlektronnyi vestnyk. — 2011. — № 4. - S. 18-25.

9. Ershov A. A. Ot «Tytanyka» do «Costa Concordia» neyspolzovannye vozmozhnosty dlia spasenyia: monohrafyia / A. A. Ershov. - Saarbrucken, Deutschland: LAPLAMBERT Academic Publishing, 2013. - 146 s. 